\title{
AUSENCIA DE CAPITALES, ESPECULACIÓN Y COMERCIANTES EN EL PUERTO DE CARTAGENA DE INDIAS A PRINCIPIOS DEL SIGLO XIX
}

\author{
Raúl Román Romero \\ Universidad Nacional de Colombia \\ Colombia
}

Vanessa Niño De Villeros

Universidad de Cartagena

Colombia 
Panorama Económico, Vol. 27 - No. 2 (Abril - Junio de 2019), pp. 429-452

Raúl Román Romero

Vanessa Niño De Villeros

JEL: N30, N36, N46

\title{
Ausencia de capitales, especulación y comerciantes en el puerto de Cartagena de Indias a principios del siglo XIX
}

\section{Resumen}

Este artículo analiza cómo en el contexto de declive económico que experimenta el puerto de Cartagena entre 1830 a 1858, la ausencia de capitales y de iniciativas empresariales exitosas llevaron a fórmulas financieras caracterizadas por la especulación y mecanismos de transacción que prolongaron la comercialización de esclavizados, violando incluso la ley de libertad de vientres emitida por el presidente de Colombia Simón Bolívar. Se analiza, además cómo la comercialización de cautivos por medio de la compraventa, y la comercialización de bienes raíces jugaron de manera conjunta un papel clave en la activación financiera y económica de la ciudad. Lo anterior vinculó, no sólo a los comerciantes reconocidos, sino a un grupo de mujeres que participaron activamente en la comercialización de esclavizados y en la compraventa de casas.

Palabras clave:Comercio, puerto de Cartagena, esclavizados, especulación, propiedad raíz, esclavitud.

\section{Absence de capitaux, de spéculation et de marchands dans le port de Carthagène des Indes au début du XIXe siècle}

\section{Résumé}

Cet article analyse comment, dans le contexte de déclin économique qu'a connu le port de Carthagène entre 1830 et 1858, l'absence de capitaux et d'initiatives commerciales réussies a conduit à des formules financières caractérisées par des mécanismes de spéculation et de transaction qui ont prolongé la commercialisation des esclaves, violant notamment la loi sur la liberté de ventre donnée par le président de la Colombie Simón Bolívar. En outre, il est analysé comment la commercialisation des captifs par la vente et l'achat et la commercialisation des biens immobiliers ont conjointement joué un rôle clé dans l'activation financière et économique de la ville. Cela était lié, non seulement à des marchands reconnus, mais à un groupe de femmes qui participaient activement à la commercialisation des esclaves et à la vente de maisons..

Mots clés: Commerce, port de Carthagène, esclave, spéculation, immobilière, esclavage.

\section{Absence of capital, speculation and merchants in the port of Cartagena de Indias at the beginning of the 19th century}

\begin{abstract}
This article analyzes how in the context of economic decline experienced by the port of Cartagena between 1830 and 1858, the absence of capital and successful business initiatives led to financial formulas characterized by speculation and transaction mechanisms that prolonged the commercialization of enslaved people, violating including the freedom of bellies law issued by the President of Colombia Simón Bolívar. In addition, it is analyzed how the commercialization of captives through the sale and purchase and the commercialization of real estate jointly played a key role in the financial and economic activation of the city. This linked, not only to recognized merchants, but to a group of women who actively participated in the commercialization of slaves and in the sale of houses.
\end{abstract}

Keywords: Commerce, Cartagena port, enslaved, speculation, real estate, slavery. 


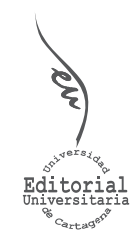

Artículo de Investigación

Ausencia de capitales, especulación y comerciantes
en el puerto de Cartagena de Indias a principios del
siglo XIX

INFORMACIÓN DEL ARTícULO

Recepción del artículo: 05/02/2019

Concepto de evaluación: 01/03/2019

Aceptación del artículo: 30/03/2019
Raúl Román Romero'

Universidad Nacional de Colombia, Colombia

Vanessa Niño De Villeros

Universidad de Cartagena, Colombia

\section{INTRODUCCIÓN}

Entre 1830 y 1858, a pesar de que el puerto de Cartagena atravesaba un pronunciado declive económico, se creía que podría reunir las condiciones necesarias para tener una posición mucho más sólida respecto al resto del país, sin embargo, este potencial no logró desarrollarse en ninguno de sus aspectos a lo largo de ese periodo. Por el contrario, la imposibilidad de hacerlo fue la que determinó que la ciudad experimentara, a mediados del siglo XIX y de forma mucho más contundente, una crisis económica sin precedentes que la condujo al colapso económico y demográfico ${ }^{2}$.

Las causas del declive económico han sido explicadas de manera general como resultado de la Independencia en los pocos estudios que se han hecho sobre este periodo, por esa razón, el interés de este artículo es presentar, más que la postración financiera de la ciudad, las dinámicas comerciales que se dieron en el marco de la misma, con un énfasis especial en las coincidencias que se dan por la ausencia de capitales y las limitaciones del comercio que se practicaba en la ciudad. Este último circunscribía su actividad a las transacciones que se daban en los circuitos de la compraventa de esclavos y de casas ${ }^{3}$

\footnotetext{
1. Autor de correspondencia: rromanr@unal.edu.co

2. Las primeras interpretaciones de esta crisis se pueden encontrar en: Theodore, Tres puertos de Colombia. Estudio sobre el desarrollo de Cartagena, Santa Marta y Barranquilla, Banco Popular, Bogotá 1973; Segovia Salas Rodolfo, "Teoría de Cartagena por qué se pierde un siglo (prólogo)", en: Bossa Herazo, Donaldo, Cartagena independiente. Tradición y desarrollo, Bogotá, Tercer Mundo.

3. Algunos trabajos en esta dirección son: Restrepo R., Jorge y Rodríguez B., Manuel, "La actividad comercial y el grupo de comerciantes de Cartagena finales del siglo XIX”, en, Estudios Sociales N 1, Medellín, 1986, págs. 43-109; Bell Lemus, Gustavo, Cartagena de Indias de la Colonia a la República, Santafé de Bogotá, Fundación Guberek 1998; Solano, Sergio Paolo, "Empresarios, proyectos de modernización e imaginarios sociales en la provincia de Cartagena durante la primera mitad del siglo XIX", en, Historia y cultura, $\mathrm{N}^{\circ} 3$, Universidad de Cartagena, 1994; Calvo Stevenson, Haroldo, "A la sombra de la Popa: El declive de Cartagena en el siglo XIX”, en, Calvo S., Haroldo- Meisel, Adolfo, Cartagena de Indias en el siglo XIX, Universidad Jorge Tadeo Lozano-Banco de la República, Bogotá, 2002; 289; Ripoll, María Teresa, "Tradición mercantil en Cartagena en el siglo XIX, en, Calvo S., Haroldo-Meisel, Adolfo, Cartagena de Indias en el siglo XIX, Cartagena, Banco de la República, 2000, pág. 38-46; Román Raúl y Vidal Antonino, "El Caribe colombiano versus centro del país: rivalidades económicas en la construcción de una economía nacional”. Investigación y Desarrollo, Vol. 19, n 1 Universidad Del Norte, Barranquilla, enero- junio de 2011, págs. 140-165.
} 


\section{LA AUSENCIA DE CAPITALES E INVERSIONES EN EL PUERTO}

En el proceso comercial y de intercambios que se presentó entre 1830 y 1858, los comerciantes jugaron un papel importante, aunque buena parte de ellos se encontraba en la quiebra como consecuencia de las pérdidas que tuvo durante los más de diez años que duró la guerra de independencia (Ripoll, 1994). No obstante, muchos aún mantenían relaciones económicas de importancia con casas comerciales internacionales y eran activos en el comercio de importación y exportación. Gosselmán (1981) describió el negocio que practicaban los comerciantes de este puerto de la siguiente manera:

La marcha de los negocios es simple, ya que se reduce a recibir las mercancías de Europa o los Estados Unidos, o a viajar a Jamaica para comprarlas personalmente; las descargan, pasan por la aduana, el grueso de la cantidad lo envían inmediatamente a Bogotá y a Mompós, y el resto es despachado para la venta en Cartagena. Pequeños comerciantes del mismo lugar o de sus alrededores compran partidas menores, las que luego ofrecen en venta. (p. 87)

Esta descripción resume bien el funcionamiento comercial que se da por el puerto de Cartagena y el formato especulativo que utilizaron los comerciantes de la plaza. Es evidente que están divididos en varias tipologías: los que importan y exportan en grandes cantidades, y una mayoría que recibe las mercaderías en consignación de manera individual o en representación de casas comerciales en Cartagena.

Obtenidas las mercancías, iniciaban las ventas o intercambios con otros comerciantes que las pagaban con metal u otros productos exportables o comerciables en la plaza. Estos últimos, que compraban de inmediato a costos menores o a crédito, las distribuían en los pequeños mercados dentro de la provincia, mientras que los comerciantes al por mayor las enviaban al interior del país. Como lo señala Gosselman (1981), cuando el canal del Dique estaba taponado, lo hacían por la vía de Mahates hacia Barranquilla para tomar la ruta del río Magdalena:

Estas mercancías deben pasar por la aduana para después ser cargadas en los famosos bongos y enviadas a Mahates, ubicado al sur de Cartagena, desde donde inician viaje en burros hasta Barranquilla. En caso contrario pueden hacer el tramo directo hasta esta última ciudad, donde se envían por vía marítima a través del río Magdalena hacia Bogotá y el interior del país. (p.87)

Los vendedores al por mayor y al por menor cumplieron un papel importante en el dinamismo comercial de la ciudad entre 1830 y 1858. Ellos movilizaron mercancías, capitales y hasta personas en medio del decadente sistema esclavista que sobrevivió hasta 1851. También se encargaron de distribuir productos hasta el interior del país y a los pequeños y fragmentarios mercados locales que se formaban en la provincia.

Antes de la década del treinta el puerto de Cartagena había despertado el interés de algunos extranjeros, especialmente ingleses, que veían ganancias favorables por el tratado comercial que existía entre Colombia e Inglaterra. En el censo de 1843 encontramos un total de 83 comerciantes extranjeros en toda la provincia que mantuvieron residencia y negocios en la ciudad. Se encuentran Henry Grice, George Watts, Daniel Gregorio Lemaitre, Eduardo Gattiker, Willian Grutt, Carlos Dean, Tomas Gordon, Gilbert Deninson, Daniel Amett, Juan Pavageau, Mariano Lindeman, Manuel Román y Picón, Pedro Maciá Doménech, entre otros. De la unión de algunos de estos 
comerciantes o de su permanencia en Cartagena surgieron algunas casas comerciales como Gattiker Lemaitre y Cia., Oxfor \& Grice, Druce Eclark y compañía, A. Atkinson \& Co., Needham Watts \& Co., Bunch \& Cia., MacDowall Atkinson \& Co. (Archivo Histórico de Cartagena, 1835) ${ }^{4}$.

De 1830 a 1858 se consolidó un grupo importante de comerciantes extranjeros que decidió vivir en la ciudad y otros de origen local que sobrevivieron a los estragos de la Independencia y lograron hacer grandes fortunas en el comercio internacional. Además de Manuel Marcelino Núñez, Juan de Francisco Martín, Manuel y José María Amador y Vicente García Del Real, también otros comerciantes estaban vinculados al comercio por este puerto: Agustín Vélez, Camilo Benedetti, Agustín Argumedo y Tomás Navarro. Para 1852 figuraron exportando diferentes productos a destinos diversos los señores Francisco Zubiría, Pedro Maciá, Ramón León Sánchez, López Porras, Henrique P. de la Vega, D. Oliveros, Jenaro Castañeda, José Jaspe, M. Gómez, J. Capella, Elbridge Foster, M. Pretelt, J. Deyegs, Jervacio Villa, C. Chiari, J. Venet y Carlos Hibles ${ }^{5}$.

Un porcentaje importante de comerciantes vivía de la especulación y de las oportunidades que les brindaban tanto el declive de la económica portuaria como algunos momentos coyunturales que eran propicios para hacer grandes ganancias. Por ejemplo, los episodios de confrontación civil, los sitios militares a la ciudad y hasta las epidemias que, como el cólera, la azotaron en 1849. Para 1831, en medio del sitio impuesto por el general Ignacio Luque al puerto de Cartagena, los vecinos de la ciudad solicitaron que las autoridades dejaran de resistirse para evitar que se propagara el hambre en medio de los elevados precios que habían adquirido los víveres de consumo diario (Corrales, 1888).

Esta actividad especulativa y usurera de algunos comerciantes fue duramente cuestionada por las autoridades y personas del común. En julio de 1849, en medio de las calamitosas consecuencias que causaba el cólera, se generó el encarecimiento de los productos de consumo básico. Al parecer, el acaparamiento de los comestibles dio pie a que se elevaran los precios de algunos alimentos. A propósito de esta situación, Juan José Nieto, como gobernador encargado, reprobó la actitud del comercio:

Se observa con bastante pena, que varios ciudadanos faltos de patriotismo i humanidad, a la vez de ser unos de muy poca utilidad i otros de ninguna en la actual época de público conflicto, lo que hacen es aprovecharse de él para procurar su ganancia en las provisiones que más consume la clase pobre, ganancia que la moral rechaza, que la religión i la honestidad común condena i que solo puede aprobar ánimos vulgares. ${ }^{6}$

Una de las medidas implementadas por el gobernador encargado para remediar la situación de los coléricos y las personas pobres de la ciudad fue nombrar a Manuel Marcelino Núñez como auxiliar del alcalde. Se trataba de uno de los comerciantes más distinguidos y respetados de la ciudad. El objetivo de dicho nombramiento fue conseguir los abastos alimenticios que necesitaba la Junta de Sanidad para suministrarlos a los enfermos del cólera y velar para que los precios de los alimentos no se elevaran a niveles inalcanzables ${ }^{7}$.

4. Archivo Histórico de Cartagena (AHC): Notaria Primera, 1835, Protocolo 19, Tomo 2, Fol. 24-25.

5. Ver lista de exportadores por meses en el puerto de Cartagena con los respectivos productos y valores exportados en: La Democracia, Cartagena, febrero 7 de 1853.

6. Semanario de la Provincia de Cartajena, Cartagena, julio 22 de 1849.

7. Semanario de la provincia de Cartajena, Cartagena, agosto 26 de 1849. 
Como consecuencia de la especulación, el crédito y los réditos se convirtieron en parte importante de las actividades de estos comerciantes, quienes en muchos casos no contaban ni con dinero contante ni con metálico para adelantar sus transacciones. De esta manera las hipotecas y compraventas de esclavos y casas se convirtieron en las principales transacciones económicas con las que se sostenían en parte el comercio internacional y algunas de las actividades económicas de la urbe.

Las transacciones comerciales registradas de manera legal en los protocolos notariales de la ciudad muestran que la compraventa de esclavos se convirtió en la actividad comercial de mayor frecuencia, seguida del negocio de casas, hipotecas y otras transacciones económicas. Un examen minucioso a estas dos actividades permite hacerse a una idea del peso que tienen en la ciudad y los principales comerciantes que las practican, así como su articulación a los procesos especulativos en la frágil economía de Cartagena ${ }^{8}$.

\section{COMERCIO Y ESCLAVITUD EN LA ECONOMÍA DEL PUERTO DE CARTAGENA}

Pese a lo que se ha dicho sobre la disminución del comercio de esclavizados en Cartagena, en la primera mitad el siglo XIX el volumen de actividades económicas relacionadas con este sugiere que si bien la importación y la exportación de dicha población desde el puerto de Cartagena era prácticamente inexistente y los esclavizados se habían reducido a un número ínfimo, las transacciones comerciales con los remanentes indican que esta práctica comercial se mantenía intacta en la ciudad y que fue importante no solo en cantidad sino en valor. En efecto, el volumen de compraventa de esclavos generó ingresos significativos que lograron mantener un comercio local medianamente fluido, así como activo un circuito económico de importación y exportación de productos y mercaderías a menor escala. En el siguiente cuadro se puede observar la caída en el número de esclavizados en la ciudad, pero no su desaparición?.

Tabla 1.

Número de esclavizados en Cartagena 1772-1851

\begin{tabular}{l|l|c|c}
\hline 1772 & 1778 & 1780 & 1851 \\
\hline 2394 & 2564 & 2107 & 171
\end{tabular}

Fuente: Para 1778, A.G.N. Milicias y Marina. Tomo 141, f.208r. Rubricado Juan Pimienta; para 1780, A.G.N. Sección Colecciones. Fondo Ortega Ricaurte, Censos 1, caja 37, documento 11. (Firmado) Roque de Quiroga. Para 1772, Eduardo G. De Piñeros. "Población de la provincia de Cartagena de Indias en el año de 1772", en Boletín Historial, Academia de Historia de Cartagena, 2019.

8. Archivo Histórico de Cartagena (AHC), Protocolos notariales de 1830 a 1851.

9. Para un análisis pionero e interesante sobre la esclavitud en la Provincia de Cartagena ver: Meisel Adolfo, "Esclavitud, mestizaje y Haciendas en la provincia de Cartagena, 1533-1551. En Bell Lemus Gustavo. El Caribe Colombiano, Barranquilla, Universidad del Norte, 1989, págs. 105-109. 
El número de cautivos en la ciudad había disminuido notoriamente, de 2.107 que había en 1780 se pasó a 171 en 1851, es decir, 71 años después la población esclava en la ciudad disminuyó en un promedio de 28 individuos por año, un número pequeño si no se tiene en cuenta que la prohibición del comercio esclavista y la ley de libertad de vientres de 1821 debieron erradicar de la ciudad esta práctica económica. Sin embargo, la supervivencia de la esclavitud en Cuba, el sur de los Estados Unidos y en Brasil puede explicar la pervivencia de este sistema de comercialización en la provincia de Cartagena hasta 1851, año en el que se decreta definitivamente la libertad de los esclavos y queda abolida su comercialización en Cartagena. Lo que sorprende es que subsistía una proporción apreciable de seres humanos cautivos. El año de la abolición de la esclavitud, participaron con el 1,7\% del total de la población de la ciudad que, llegaba a 9.896 habitantes.

Lo anterior hace suponer que a lo largo de 71 años la esclavitud se resistió a desaparecer, más aún cuando desde 1821 se otorgó la libertad a los nacidos y 31 años después aún subsistía una dimensión destacable de esta práctica comercial en su formato de compraventa, a tal extremo que en la década del cuarenta se seguían vendiendo menores, es decir, nacidos libres, a precios inferiores. Por ejemplo, María de los Santos Riba, vecina de la Villa de Tolú y residente en Cartagena, como apoderada y esposa del señor Manuel González le vendió al doctor Pedro Francisco Castellón tres esclavizadas nombradas María Josefa por 150 pesos; María Rosario, hija comprendida en la manumisión, por 50 pesos, y Pabla en 200 pesos, "las cuales les pertenecían a su legítimo marido por haberlas comprado al señor Eduardo Grisolle". ${ }^{10}$

La situación de la esclavitud se magnifica si observamos entre 1835 y 1843 el número en la Provincia de Cartagena. En estos ocho años pasó de 3.135 esclavos a 2.325, es decir, presentó una disminución de 810, equivalente a un promedio de 101 por año. El cantón de esta provincia que vivió una mayor disminución fue San Andrés isla, en 373 esclavos, seguido del cantón de Mahates, con 285, Lorica con 218, Soledad con 45, Corozal con 23, Sabanalarga con 11 y Barranquilla con 10.

Tabla 2.

Esclavizados en la provincia de Cartagena por Cantones, 1835-1843

\begin{tabular}{lll}
\hline Cantones/esclavizados & $\mathbf{1 8 3 5}$ & $\mathbf{1 8 4 3}$ \\
\hline Cartagena & 525 & 639 \\
Barranquilla & 131 & 121 \\
Soledad & 173 & 128 \\
Sabanalarga & 177 & 166 \\
Mahates & 584 & 299 \\
Corozal & 241 & 218 \\
Chinú & 134 & 175 \\
Lorica & 536 & 318 \\
San Andrés & 634 & 261 \\
\hline Totales & 3135 & 2325
\end{tabular}

Fuente: Elaboración propia de acuerdo a los datos de AGN Fondo Enrique Ortega Ricaurte, caja 102, Carpeta 373, f, 887 y Censo General de población 1843, en Semanario de la Provincia de Cartajena, Cartagena, septiembre 17 de 1843.

10. Archivo Histórico de Cartagena (AHC). Protocolos notariales. Notaria primera, 1840-1841, Prot. 30, Tomo 3 , Fol. 118. 
En este descenso del número de esclavizados las únicas particularidades se presentaron con los cantones de Cartagena y Chinú, donde se dio un crecimiento en el número de esclavos, para el primero de 114 y para el segundo de 41. En el caso de Cartagena es explicable porque la ciudad fue un centro importante de comercio internacional y en ella se daba un número elevado de transacciones comerciales que en buena parte se realizaban mediante el intercambio con esclavos, lo que generó la convergencia de estos en la ciudad, procedentes de otros cantones o distritos parroquiales como Tolú, Corozal, Mahates, Soledad y las inmediaciones del puerto de Cartagena ${ }^{11}$. La tendencia en el número de esclavos se puede apreciar en la siguiente gráfica.

Gráfica 1. Esclavizados en el cantón de Cartagena, 1835-1851

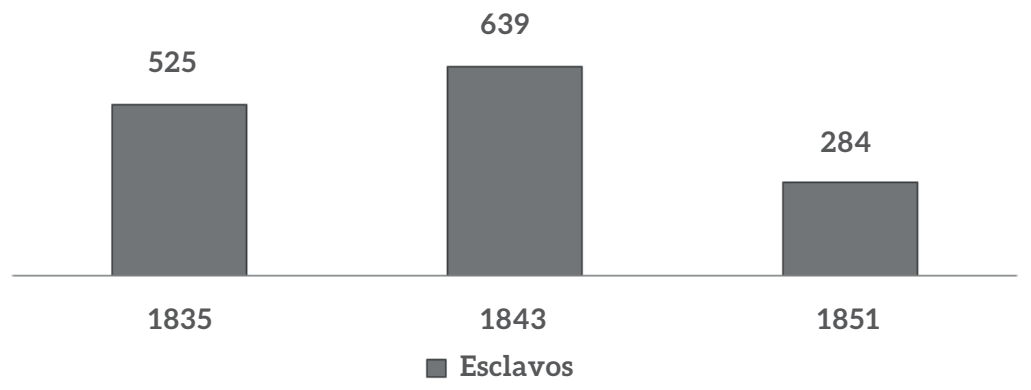

Fuente: Elaboración propia de acuerdo a los datos de AGN, Fondo Enrique Ortega Ricaurte, caja 102, Carpeta 373, F.887 y Censo General de población 1843, en Semanario de la Provincia de Cartajena, Cartagena, septiembre 17 de 1843.

En la provincia de Cartagena, fue en el cantón del mismo nombre donde pervivieron los restos del sistema esclavista, aunque de 1843 a 1851 se presentó una disminución de 355 cautivos a un promedio por año de 44. Lo cierto es que todavía en el año de la abolición existían en el cantón 284 esclavos, concentrados casi en su totalidad en el puerto. En 1835 los esclavos de este territorio participaron con el 2,3\% del total de la población, en 1843 con el 3,1\% y en 1851 con el 1,7\%. Lo curioso de esta tardía desaparición de la esclavitud es que, durante estos años, aún la compraventa de esclavos era relativamente importante en las fluctuaciones de capital de la ciudad ${ }^{12}$.

\section{COMERCIANTES Y COMPRAVENTA DE ESCLAVIZADOS EN LA ECONOMÍA LOCAL}

Entre 1830 y 1851 se registraron en la notaría 946 transacciones de compraventa de esclavizados. Aunque no todas se legalizaban en los protocolos notariales, esta cifra permite un acercamiento al número de transacciones que se realizaron en el puerto de Cartagena en los años señalados. Estas compraventas ascendieron a 183.927 pesos, una

\footnotetext{
11. Ver Archivo Histórico de Cartagena (AHC): Protocolos notariales, Notaría Primera, 1831, Prot, 15, Tomo, 2, fs, 28-29; 1835, Prot, 48, Tomo, 4, fs, 64-65; 1835, Prot, 9, Tomo, 7, fs, 14-161; 1835, Prot.5, Tomo, 6, fs, 7; 844-1845; Prot, 53, tomo, 1, fs, 194-197; 1842, Prot, 86, Tomo, 1, fs, 245r-247.

12. Para un análisis de la prolongación de la esclavitud en Cuba ver Piqueras José Antonio, Plantación espacios agrarios y esclavitud en la cuba colonial, Habana, Casa de Las Américas-Universidad Jaume I, 2017.
} 
cifra que, aunque aproximada y pequeña comparada con los años de la Colonia, tuvo significación en la frágil economía de la ciudad en el periodo estudiado.

con el $64 \%$, equivalente a 117.462 pesos, y los hombres con el $36 \%$, representado en 65.036 pesos, esto se debió a que la compraventa de mujeres cautivas fue mucho mayor que la de los hombres. En efecto, de las 946 transacciones, 322, es decir, el 34\%, correspondieron al sexo masculino, y 616, que representan el 65,1\%, al femenino. Solo 8 transacciones, equivalentes al 0,9, no se pudieron identificar en términos de sexo ${ }^{13}$.

Es importante destacar que, aunque fueron 946 transacciones las que se realizaron, solo participaron de la compraventa un total de 724 con esclavizados, ya que 222 de ellos estuvieron en más de una operación, algunos llegaron a venderse hasta 11 veces y las más vendidas fueron mujeres. Este dato es sumamente importante porque permite entender la vitalidad que toma la compraventa en la economía de la ciudad, sobre todo si tenemos presente que en el cantón de Cartagena entre los años de 1835 y 1851 no vivían más de los 639 esclavizados, lo que evidencia que se está comercializando un número mayor de esclavos de aquellos que habitan la plaza. A esto hay que agregar que se realizaron 11 manumisiones, 2 de ellas compradas por los mismos esclavos, cuyo valor asciende a 410 pesos.

Tabla 3.

Compraventa de esclavizados por valor y sexo en Cartagena, 1830-1835

\begin{tabular}{|c|c|c|c|c|c|c|c|c|}
\hline \multirow[b]{2}{*}{ Año } & \multicolumn{2}{|c|}{ Hombres } & \multicolumn{2}{|c|}{ Mujeres } & \multicolumn{2}{|c|}{ Sin información } & \multicolumn{2}{|c|}{ Totales } \\
\hline & Valor & Transacciones & Valor & Transacciones & Valor & Transacciones & Valores & Transacciones \\
\hline 1830 & 3930 & 19 & 5364 & 25 & & & 9294 & 44 \\
\hline 1831 & 7456 & 37 & 10750 & 51 & 250 & 1 & 18456 & 89 \\
\hline 1832 & 12818 & 62 & 24842 & 113 & & & 37660 & 175 \\
\hline 1833 & 5305 & 26 & 12395 & 63 & 400 & 2 & 18100 & 91 \\
\hline 1834 & 1623 & 7 & 2347 & 13 & & & 3970 & 20 \\
\hline 1835 & 11794 & 56 & 16612 & 88 & & & 28405,5 & 144 \\
\hline 1836 & 1650 & 7 & 1395 & 7 & & & 3045 & 14 \\
\hline 1837 & 400 & 2 & 600 & 3 & & & 1000 & 5 \\
\hline 1838 & 240 & 1 & 370 & 2 & & & 610 & 3 \\
\hline 1839 & 425 & 2 & 150 & 1 & & & 575 & 3 \\
\hline 1840 & 1950 & 9 & 5340 & 29 & & & 7290 & 38 \\
\hline 1841 & 1930 & 8 & 3041 & 16 & 180 & 1 & 5151 & 25 \\
\hline 1842 & 2640 & 14 & 9353 & 55 & & & 11993 & 69 \\
\hline 1843 & 1850 & 12 & 9298 & 54 & & & 11148 & 66 \\
\hline 1844 & 3265 & 15 & 3581 & 22 & & & 6846 & 37 \\
\hline 1845 & 2192 & 13 & 2812,5 & 16 & & & 5004,5 & 29 \\
\hline 1846 & 968 & 5 & 1043 & 6 & 100 & 1 & 2111 & 12 \\
\hline 1847 & 1035 & 6 & 2163 & 13 & 400 & 2 & 3598 & 21 \\
\hline 1848 & 950 & 6 & 1663 & 12 & 100 & 1 & 2713 & 19 \\
\hline 1849 & 1230 & 7 & 1680 & 10 & & & 2910 & 17 \\
\hline 1850 & 1385 & 8 & 2412 & 15 & & & 3797 & 23 \\
\hline 1851 & & & 250 & 2 & & & 250 & 2 \\
\hline Total & 65036 & 322 & 117462 & 616 & 1430 & 8 & 183927 & 946 \\
\hline
\end{tabular}

Fuente: Elaboración Propia con base a AHC (Protocolos Notariales, Notaría Primera. 1830-1851)

13. Para un análisis similar en el caso de la ciudad de Santa Marta ver Elías Caro Jorge, "El puerto de Santa Marta: determinantes del crecimiento y desarrollo de una ciudad caribeña 1810-1860, en: Elías Caro Jorge y Vidal Ortega Antonino, Ciudades portuarias en la Gran Cuenca del Caribe, Barranquilla, Universidad del Norte, Universidad del Magdalena, 2010. págs. 328-354. Ver también para esta ciudad a Romero Jaramillo Dolcey, esclavitud en la provincia de Santa Marta 1791-1851, Santa Marta, Fondo de Autores Magdalenenses, Instituto de Cultura y Turismo del Magdalena, 1997. 
Sin duda, se trata de un comercio nada desdeñable en los años finales de la abolición de la esclavitud. Esta situación nos autoriza a proponer que en la ciudad de Cartagena, en los treinta años anteriores a la finalización de la esclavitud, se mantiene la comercialización de cautivos, ya que concentra un número importante de éstos, provenientes de otros cantones que funcionan dentro de las relaciones de intercambio de mercancías y se convierten en un elemento que movilizó los flujos de capital de la endeble economía de la ciudad de Cartagena. En la gráfica 2 se pueden apreciar los 19 esclavizados más vendidos.

Tabla 3.

Compraventa de esclavizados por valor y sexo en Cartagena, 1830-1835

\begin{tabular}{|c|c|c|c|c|c|c|c|c|}
\hline \multirow[b]{2}{*}{ Año } & \multicolumn{2}{|c|}{ Hombres } & \multicolumn{2}{|c|}{ Mujeres } & \multicolumn{2}{|c|}{ Sin información } & \multicolumn{2}{|r|}{ Totales } \\
\hline & Valor & Transacciones & Valor & Transacciones & Valor & Transacciones & Valores & | Transacciones \\
\hline 1830 & 3930 & 19 & 5364 & 25 & & & 9294 & 44 \\
\hline 1831 & 7456 & 37 & 10750 & 51 & 250 & 1 & 18456 & 89 \\
\hline 1832 & 12818 & 62 & 24842 & 113 & & & 37660 & 175 \\
\hline 1833 & 5305 & 26 & 12395 & 63 & 400 & 2 & 18100 & 91 \\
\hline 1834 & 1623 & 7 & 2347 & 13 & & & 3970 & 20 \\
\hline 1835 & 11794 & 56 & 16612 & 88 & & & 28405,5 & 144 \\
\hline 1836 & 1650 & 7 & 1395 & 7 & & & 3045 & 14 \\
\hline 1837 & 400 & 2 & 600 & 3 & & & 1000 & 5 \\
\hline 1838 & 240 & 1 & 370 & 2 & & & 610 & 3 \\
\hline 1839 & 425 & 2 & 150 & 1 & & & 575 & 3 \\
\hline 1840 & 1950 & 9 & 5340 & 29 & & & 7290 & 38 \\
\hline 1841 & 1930 & 8 & 3041 & 16 & 180 & 1 & 5151 & 25 \\
\hline 1842 & 2640 & 14 & 9353 & 55 & & & 11993 & 69 \\
\hline 1843 & 1850 & 12 & 9298 & 54 & & & 11148 & 66 \\
\hline 1844 & 3265 & 15 & 3581 & 22 & & & 6846 & 37 \\
\hline 1845 & 2192 & 13 & 2812,5 & 16 & & & 5004,5 & 29 \\
\hline 1846 & 968 & 5 & 1043 & 6 & 100 & 1 & 2111 & 12 \\
\hline 1847 & 1035 & 6 & 2163 & 13 & 400 & 2 & 3598 & 21 \\
\hline 1848 & 950 & 6 & 1663 & 12 & 100 & 1 & 2713 & 19 \\
\hline 1849 & 1230 & 7 & 1680 & 10 & & & 2910 & 17 \\
\hline 1850 & 1385 & 8 & 2412 & 15 & & & 3797 & 23 \\
\hline 1851 & & & 250 & 2 & & & 250 & 2 \\
\hline Total & 65036 & 322 & 117462 & 616 & 1430 & 8 & 183927 & 946 \\
\hline
\end{tabular}

Fuente: Elaboración Propia con base a AHC (Protocolos Notariales, Notaría Primera. 1830-1851)

Las esclavizadas, respecto a los varones, también son las que participan en la mayor cantidad de transacciones y con un valor adicional, ello se explica por su capacidad productiva y por las labores que desempeñaban, las cuales les generaban ingresos importantes a sus dueños. La suma entre las primeras cinco más vendidas supera los 7.000 pesos, una cantidad importante para la realización de inversiones en una economía en declive como la cartagenera por estos años ${ }^{14}$.

Dentro de los que comerciaban con esclavizados, muchas eran también mujeres. Aunque desconocidas por la historiografía, en algunos casos se trataba de las esposas de

14. Para un análisis de la mujer al servicio de la economía cubana ver Hevia Oilda, "Mujeres negras y mulatas en la economía de servicios en La Habana colonial siglos XVI y XVII", en: Piqueras José Antonio, Plantación espacios agrarios y esclavitud en la cuba colonial, Habana, Casa de Las Américas-Universidad Jaume I, 2017, pág. 439-462 
comerciantes destacados. Ellas participaron activamente del negocio, de hecho, en los años de estudio la mayor compradora de esclavos fue Ana De León de Argumedo, esposa de Agustín de Argumedo, uno de los comerciantes más respetados de la ciudad e hijo de Pedro Rodríguez de Argumedo, secretario de la gobernación de la isla de Trinidad hasta el año de 1799. Ana De León realizó una inversión de 7.156 pesos en compra de cautivos.

La segunda compradora más importante fue María Josefa Puello, quien figura como esposa de Pedro Medrano, al parecer uno de los mulatos más destacados en el proceso de independencia, pero de los que muy poco se sabe. María Josefa Puello participó con 3.010 pesos. El tercer lugar en compras de esclavos también lo ocupa una mujer, se trata de María Josefa Viñas, hija del peninsular José Viña de Cataluña, casada con José María de Alandete, hijo a su vez de José Mateo Alandete. María Josefa participó de las compras con 2.000 pesos $^{15}$.

El cuarto lugar es para Teresa Navarro de La Espriella, quien participó con 1.620 pesos, posteriormente, Fernando De Pombo, hijo del ilustrado José Ignacio de Pombo, participó con 1.556 pesos. Le sigue Carlos Dían, comerciante radicado en la ciudad, quien invirtió 1.450 pesos, y después, otros comerciantes destacados y mujeres que tuvieron una participación importante, como Tomasa Real de Navarro y Rafaela Polanco de Román, esposa de Manuel Román y Picón, padres de Soledad Román, y H. L. Román, entre otros. En el siguiente gráfico se pueden ver los principales compradores de esclavos en el periodo de estudio.

Gráfica 3. Compradores de esclavizados e inversión en Cartagena, 1830-1851

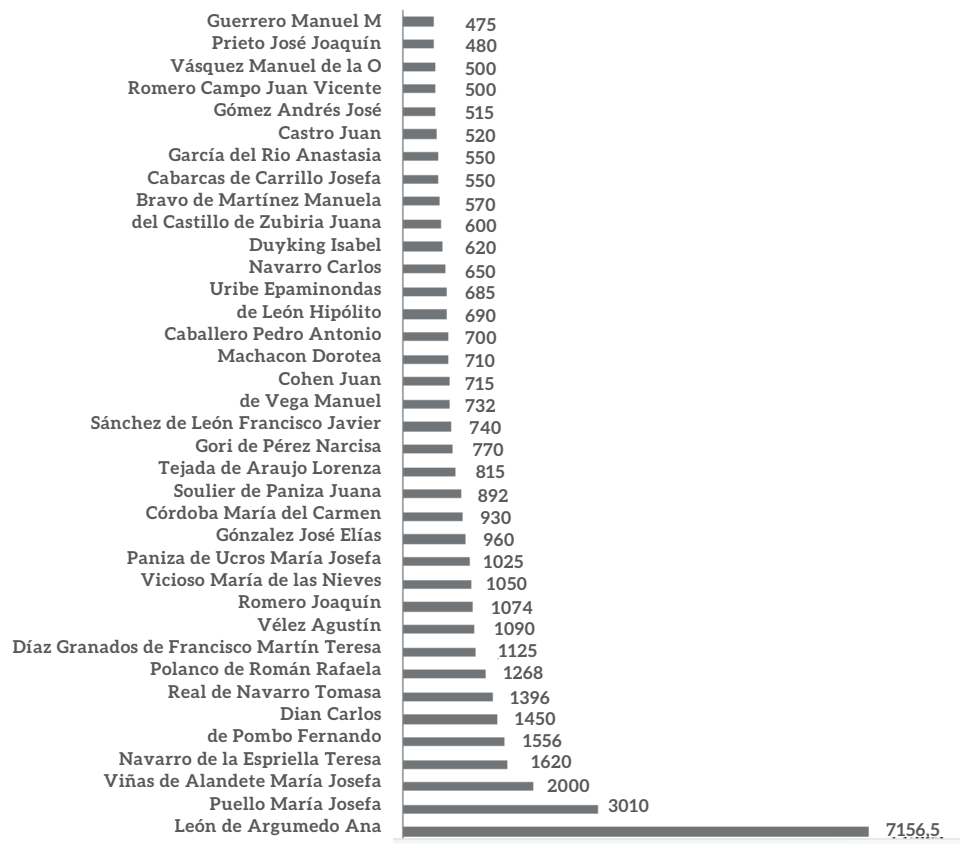

Fuente: Elaboración Propia con base a AHC (Protocolos Notariales, Notaría Primera, 1830-1851)

15. Para aproximarse a la actuación de los Médranos en el proceso de independencia ver: Múnera (2008). El fracaso de la nación, región, raza y clase en el Caribe. Bogotá: Norma. 
Siguen en orden de inversión, Teresa Díaz Granados de Francisco-Matín, esposa del Comerciante Narciso Francisco de Martín; Agustín Vélez, comerciante destacado de la ciudad; Joaquín Romero, hijo de Pedro Romero, líder de la independencia y María Josefa Paniza de Ucros, esposa de Vicente Ucros, quien ocupó importantes cargos en la ciudad $^{16}$. Muchos de los comerciantes hombres y mujeres que participaron en la compra de esclavizados también lo hicieron en la venta, aunque no en la misma medida. En este punto aparece como la mayor vendedora Ana León de Argumedo, cuyas ventas de esclavos ascienden a un valor de 3.008 pesos; le sigue, al igual que en las compras, María Josefa Puello, con 2.760 pesos; posteriormente, Fernando de Pombo, con 2.346 pesos y Agustín Vélez, con 2.155 pesos.

\section{Gráfica 4. Vendedores de esclavizados y valores en Cartagena, 1830-1851}

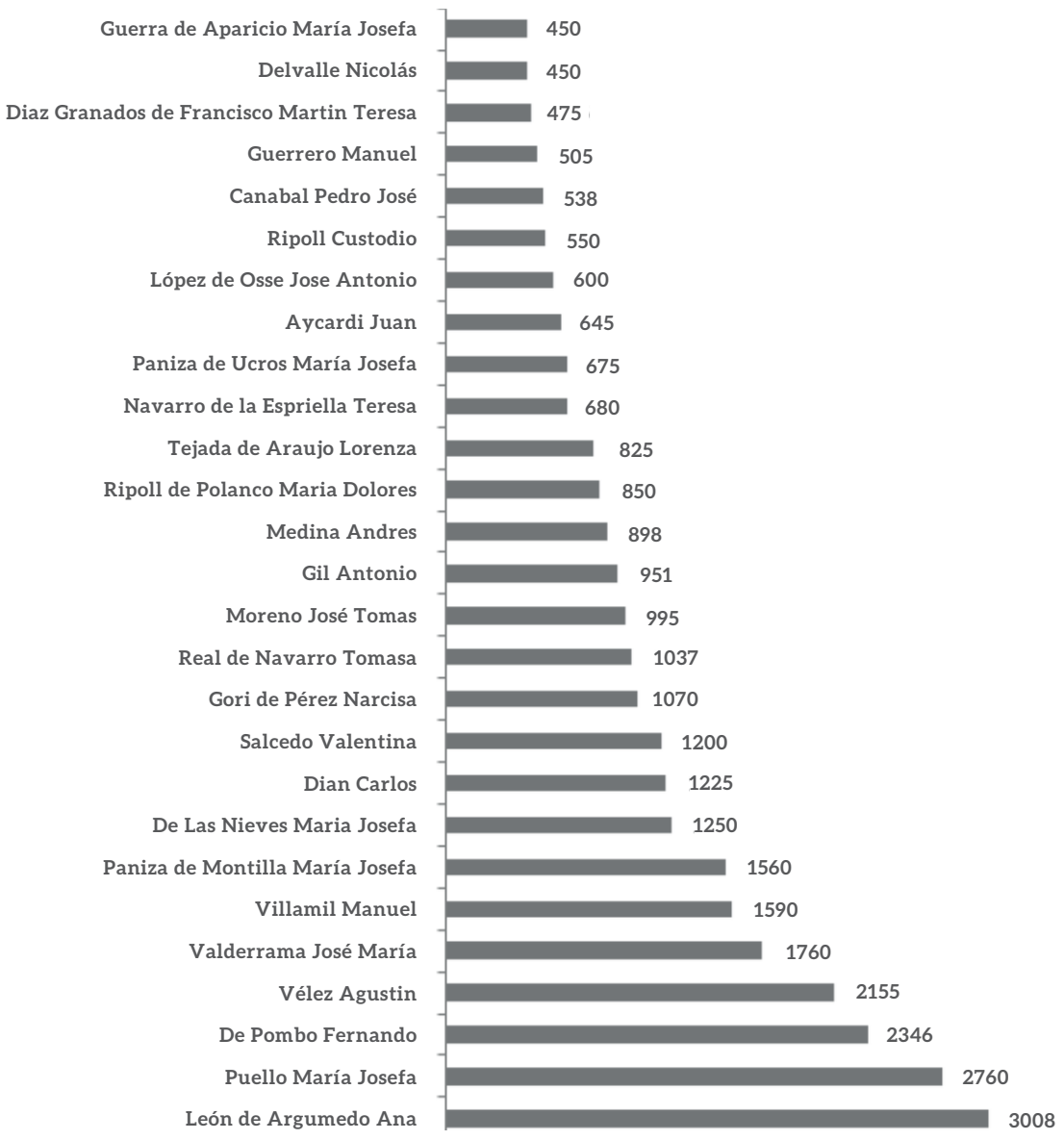

Fuente: Elaboración Propia con base en AHC (Protocolos Notariales, Notaría Primera, 1830-1851)

16. Un análisis puntual y detallado de estas transacciones pondría en evidencia la participación de familias prestantes que sobrevivieron a la Independencia, como también el ascenso de otras que encontraron en ese hecho histórico la posibilidad de ocupar un lugar destacado en la estructura social y económica de la declinante ciudad de cartagenera. 
Continúan en orden descendente José María Valderrama, con 1.760 pesos; Manuela Villamil, con 1590 pesos; María Josefa Paniza de Montilla, esposa del General Mariano Montilla y exgobernador de la provincia, con un valor por venta de 1.560 pesos; María Josefa De Las Nieves, con 1.250 pesos y Carlos Dian, entre otros, con 1.225 pesos.

Curiosamente, Ana León de Argumedo, María Josefa Puello, Teresa Navarro de la Espriella, Teresa Díaz Granados de Francisco-Matín y María Josefa Paniza de Ucros, entre otras, realizaron mayores inversiones por compra de esclavos que por la venta, por ejemplo, la primera invirtió 7.156 pesos en compra y por venta solo obtuvo 3008 , un poco menos de la mitad, la segunda invirtió en compra 3010 pesos y realizó ventas por 2.760 pesos, mientras que comerciantes como Fernando de Pombo invirtieron en compras menos cantidad de la que obtuvieron en ventas. En este último caso, invirtió en compras 1.556 y obtuvo en ventas 2.346, mientras que Agustín Vélez invirtió 1.090 pesos y obtuvo $2.155^{17}$.

Muy probablemente las mujeres de algunos comerciantes solo invertían en este tipo de transacciones y utilizaban a los esclavos para obtener ganancias diarias, a diferencia de los comerciantes -en algunos casos sus esposos- quienes diversificaban las inversiones y utilizaban a los esclavos como garantía, pago, abono de deudas y de réditos. En todos los casos las inversiones y ventas superan el capital total que suma el de los esclavos, lo que hace evidente que seguían generando ganancias significativas en el concierto de la especulación comercial $^{18}$. Por eso encontramos que en el censo de 1851 de la sección cuarta del Barrio de la Catedral muchas de las esclavas y esclavos tienen oficios definidos como cocineras, lavadoras o aplanchadoras, y en el caso de los hombres, carpinteros o carreteros. Es decir, estos esclavos les producían a sus dueñas unos jornales diarios, como lo muestra la siguiente gráfica:

Gráfica 5. Distribución de esclavizados por oficios en la sección cuarta del barrio de la Catedral 1851

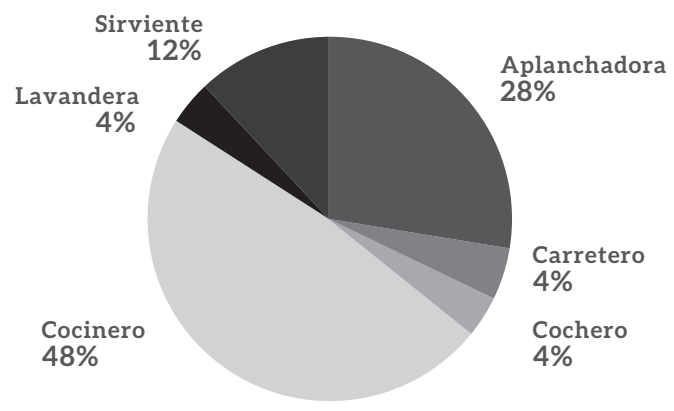

Fuente: Archivo Histórico de Cartagena, Caja Censos, censo de La Catedral 1851

17. Para referencias de esclavizados en las islas de San Andrés y Providencia ver: Meisel (2016). "La estructura económica de San Andres y Providencia en 1846", en. Román Raúl, (ed) Economía del caribe colombiano y Construcción de nación 1770-1930. Bogotá: Universidad Nacional de Colombia. También, Vidal y Ramos (2019). "Labradores y esclavizados de la isla de San Andrés en el comercio del Caribe occidental y América Central a finales del siglo XVIII", en Román Raúl y Vidal Antonino (Ed) Memorias, historias y olvidos Colonialismo, sociedad y política en San Andrés y Providencia. Bogotá: Universidad Nacional de Colombia.

18. Para un análisis de la esclavitud prolongada en el Caribe ver Moreno, M. (1978). El ingenio complejo económico social cubano del azúcar, ciencias sociales, La Habana. La idea de una segunda esclavitud puede verse en Tomich, D. (1998). The second slavery: Bonded labor and the tranformation of the Nineteenth Century world economy, en Ramires Francisco,(ed) Rethinking the nineeteenth century: movements and contradictions, Westport: Greenwood press. 
Las transacciones realizadas con los remanentes de la esclavitud en la ciudad se convirtieron en una fuente de ingresos y en un elemento que generó apreciables flujos de capital en el contexto del declive económico de Cartagena después de la Independencia. Estas, sin embargo, no fueron las únicas de compraventa con las que los comerciantes especularon y lograron obtener algunos flujos de capitales para adelantar sus negocios, pues la compraventa de casas fue unas ocho veces mayor a la de esclavizados y se convirtió en una práctica económica significativa en esta coyuntura de crisis, que inyectó importantes flujos de capital a las actividades financieras de la ciudad.

\section{COMPRAVENTA DE PROPIEDAD RAÍZ EN LA ECONOMÍA LOCAL DE CARTAGENA}

La compraventa de bienes raíces, especialmente casas, también fue una de las transacciones económicas que generó flujos de capital al frágil circuito financiero del puerto cartagenero. Entre 1830 y 1851 se registraron en protocolos notariales 453 transacciones con casas, que implicaron un número 558 compraventas, debido a que las transacciones se hacían hasta once veces en algunos casos y se repetían cuando se realizaban previa hipoteca y se cancelaban obligaciones entre un año y otro. Estas transacciones representaron un capital de aproximadamente 893.609 pesos $^{19}$. Durante estos años fueron objeto de la compraventa 442 casas, de las cuales 256 eran bajas, entre ellas 148 de piedra madera y teja, y 186 casas altas, de las cuales 84 eran de piedra, madera y teja, también había 11 "bujíos". ${ }^{20}$ La distribución de los valores de esta compraventa por año se puede ver en la siguiente gráfica.

Gráfica 6. Valores de compraventa de casas Cartagena, 1831-1851

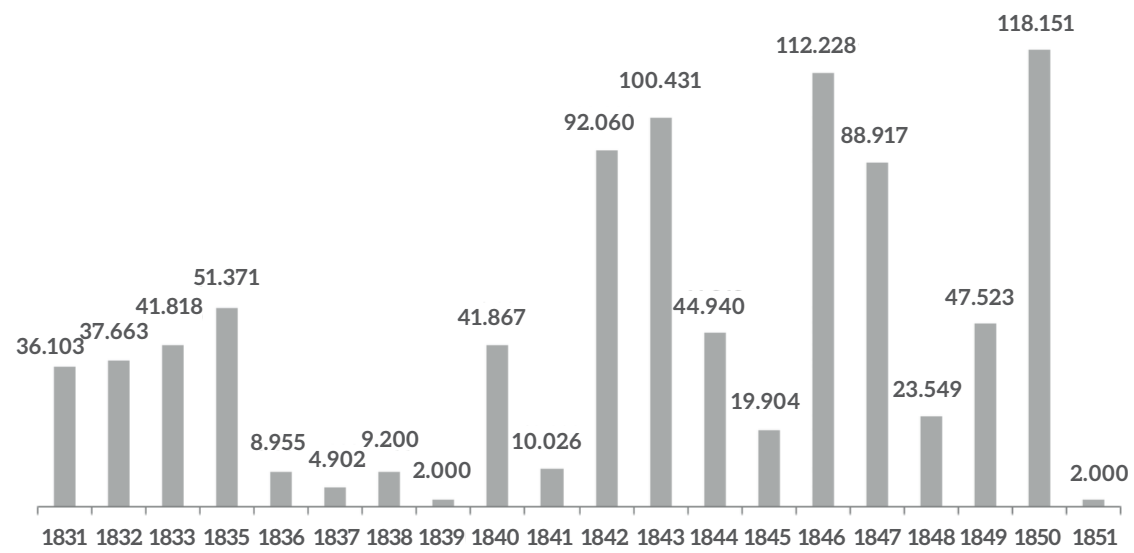

Fuente: Elaboración Propia. AHC, Protocolos Notariales, Notaría Primera, 1830-1851

\footnotetext{
19. Seguramente el valor de las compraventas es mayor, ya que no aparecen contabilizados los años de 1830 y 1834 . 20. Las casas altas eran aquellas de dos pisos, las baja solo un piso, se diferenciaban por el techo si eran en tejas o paja y los bujios eran en madera y techos de paja.
} 
Es importante anotar que 52 de estas casas no registran el valor de la transacción, lo que disminuye el total de estas operaciones financieras en la ciudad. Como una manera de aproximarnos al monto completo podemos utilizar el valor promedio que arrojan las transacciones por estos años, que es de 1.601 pesos por casa ${ }^{21}$, lo que daría una cifra de 83.275 pesos, que si se suma a los 893.609 pesos de las compraventas que tienen valor da un total aproximado de 976.883 pesos para las compraventas de casas en los años de estudio. Esta no es una suma desdeñable, dadas las características comerciales de Cartagena que, al parecer, no cuenta con un grupo de empresarios con solidez económica para la inversión, y aunque solo unos pocos comerciantes se pueden dar el lujo de hacer inversiones de alguna consideración, realmente no se arriesgaron a efectuarlas.

Es muy probable que algunas transacciones se hicieran de manera directa bajo palabra, lo que no se registra notarialmente, por eso suponemos que ascendieron a un valor mayor del notariado. El año que alcanzó el tope la compraventa fue 1850, con un monto de 118.151 pesos, que representan el 13,2\% del valor total de compraventas de casas, seguido del año 1846, con un monto de 112.228 pesos, equivalentes al 12,5\%. Curiosamente le siguen 1843, con 100.431pesos, que representan el 11,2\%, y 1842 con 92.060 pesos, equivalentes al 10,3\%. Estos dos últimos años atraviesan las consecuencias de la Guerra de los Supremos.

Lo anterior indica que los años en que la ciudad se vinculaba a las guerras que vivía el país se acrecentaban las transacciones de propiedad raíz y, de seguro, la especulación comercial. En términos generales, estos cuatro años, pese a lo convulsos, concentran un $45 \%$ del valor total de las transacciones. El comerciante que participó con el mayor valor de compras fue Nicolás Bonoli, que invirtió un capital de 109.850 pesos, equivalentes al $12,3 \%$ del monto total de las transacciones registradas notarialmente, en segundo lugar, se encuentran los hermanos Truco, Candelaria y Juan Bautista, que invirtieron 24.213 pesos, equivalentes al 2,7\%. Le siguen Henrique Grice, quien participa con 18.760 pesos, que representan el 2,1\%; Felipe Gonzáles y Petrona Cabarcas, que invierten 15.625 pesos (1,7\%); Vicente García del Real, que participa con 15.000 pesos (1,6\%), entre otros. También figuran como compradores la Fundación Juan Infanzón, que invierte 12.600 pesos, el Monasterio de las Carmelitas Descalzas, con 9.300 y los pobres y presos de la Cárcel, con 3.000 pesos, para un total de 24.900 .

Dentro de los comerciantes reconocidos en la ciudad que aparecen realizando compras de casas se encuentran Agustín Vélez, que invierte un capital de 12.000 pesos; Rafaela Polanco de Román, que participa de la compraventa de casas con 11.609 pesos; Pedro Maciá, con \$11.100 pesos; Senén Benedetti, con 10.060; Juan Vicente Romero, con 9.500 pesos, entre otros que se destacaron por diversas actividades en el comercio de la ciudad. A diferencia de las compraventas de esclavos, las de casas están casi en su totalidad bajo el control de varones, con algunas excepciones, como se puede apreciar en el siguiente gráfico.

21. Utilizamos el valor promedio de la compraventa de casas que están registradas en los protocolos notariales. 
Gráfica 7. Compradores casas y valores de compra en Cartagena, 1830-1851

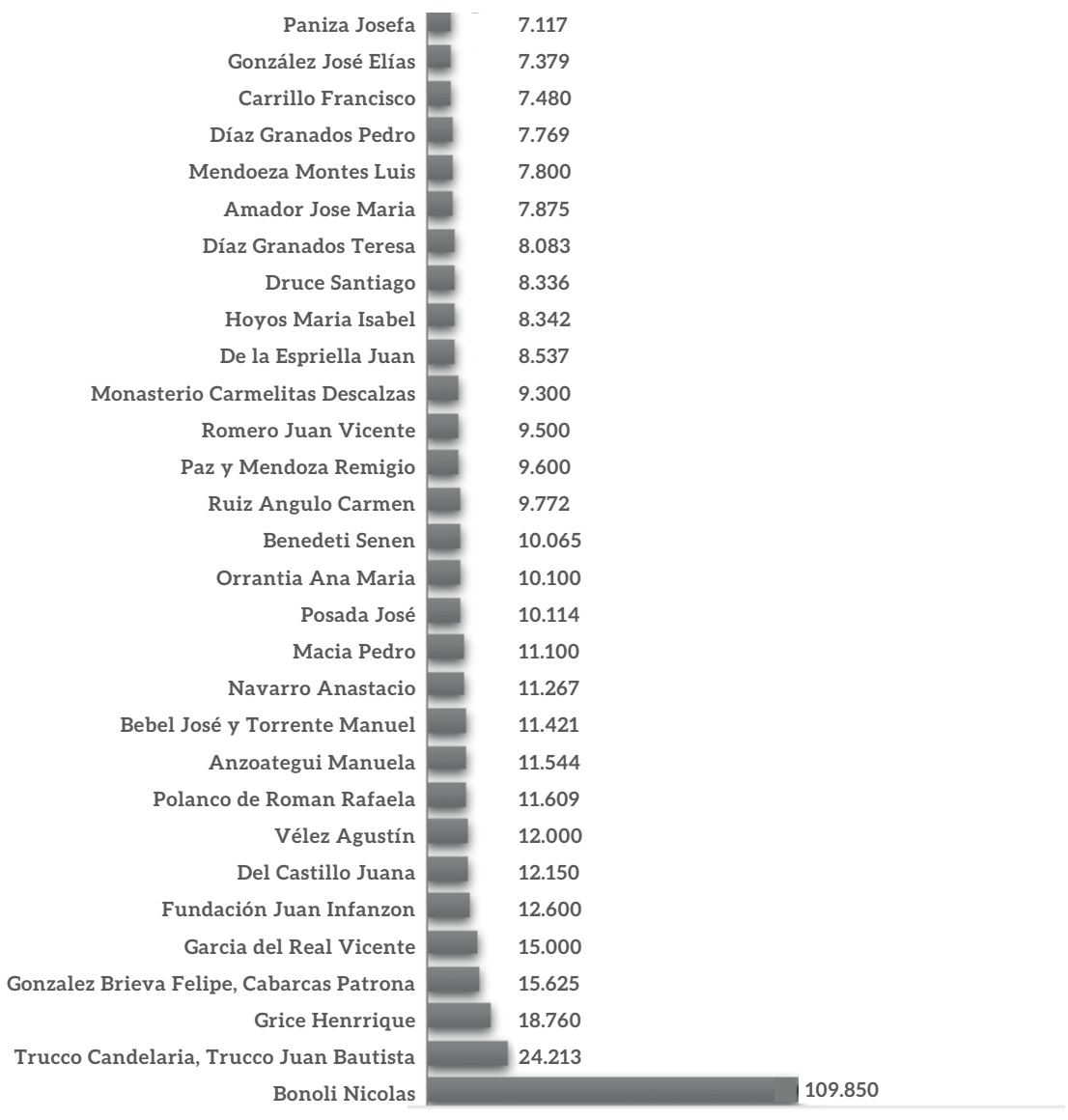

Fuente: Elaboración Propia. AHC, Protocolos Notariales, Notaría Primera, 1830-1851

Al efectuar una transacción, existen pocas coincidencias entre compradores y vendedores, pues muchos de los que compran no aparecen vendiendo y viceversa, sin embargo, existen algunas correlaciones de comerciantes que compran y venden, el más destacado es Pedro Maciá, quien compra casas por un valor de 11.100 pesos y aparece vendiendo por un monto de 18.217 pesos, y su esposa, por 18.000 pesos, sin que esta aparezca entre los primeros 35 compradores de casas. Los esposos venden casas por un total de 36.217 pesos, lo que indica un negocio de familia. También Nicolás Boloni realiza ventas por 15.625 pesos, un monto muy inferior al utilizado para las compras, mientras que Vicente García del Real vende por 10.680 pesos, por debajo del valor empleado en las compras.

Estas ventas por valores inferiores a los de las compras se explican porque la compraventa de casas en la mayoría de los casos eran cancelaciones de hipotecas, ya que los comerciantes que tenían más liquidez les prestaban a los comerciantes con menor capacidad económica, que eran la mayoría en esta empobrecida ciudad. A cambio, 
estos hipotecaban sus casas y luego pagaban intereses muy altos para recuperar sus propiedades, sin embargo, este tipo de transacciones solo las realizaban comerciantes muy seguros de sus ganancias y aquellos que tenían solvencia económica para efectuar los préstamos.

Quizá uno de los comerciantes más acaudalados y que más se lucró de los réditos que generaba esta práctica hipotecaria fue Manuel Marcelino Núñez, quien apareció durante estos años como el mayor vendedor de casas. El monto de sus ventas asciende a 115.421 pesos. Resultó que el mayor comprador de Núñez fue Nicolás Bonoli, quien figuró como el mayor comprador de casas en estos años. Apareció comprándole a Núñez en el año de 1842 un total de 11 casas de piedra, madera y teja en el barrio Santo Toribio y Catedral, ubicadas en las calles de los Siete Infantes y San Agustín, por un valor aproximado de 22.500 pesos. En 1843 nuevamente aparece cancelándole a Núñez una hipoteca de 11 casas en las calles de San Agustín y Lozano, por un valor de 30.000 pesos, y en el año de 1846, nuevamente Bonoli le cancela a Núñez dos obligaciones hipotecarias por 18 casas altas y bajas de piedra, madera y teja, la suma de 47.000 pesos. En total, Bonoli le pagó a Núñez un total de 97.500 pesos, valor que sumado a otras compras o pagos que hizo de casas lo convirtieron en el mayor comprador, y a M.M Núñez, en el que realizó las ventas más altas ${ }^{22}$. Para detallar los vendedores destacados de casas en el periodo estudiado ver la siguiente gráfica:

Gráfica 8. Vendedores de casas en Cartagena 1830-1851

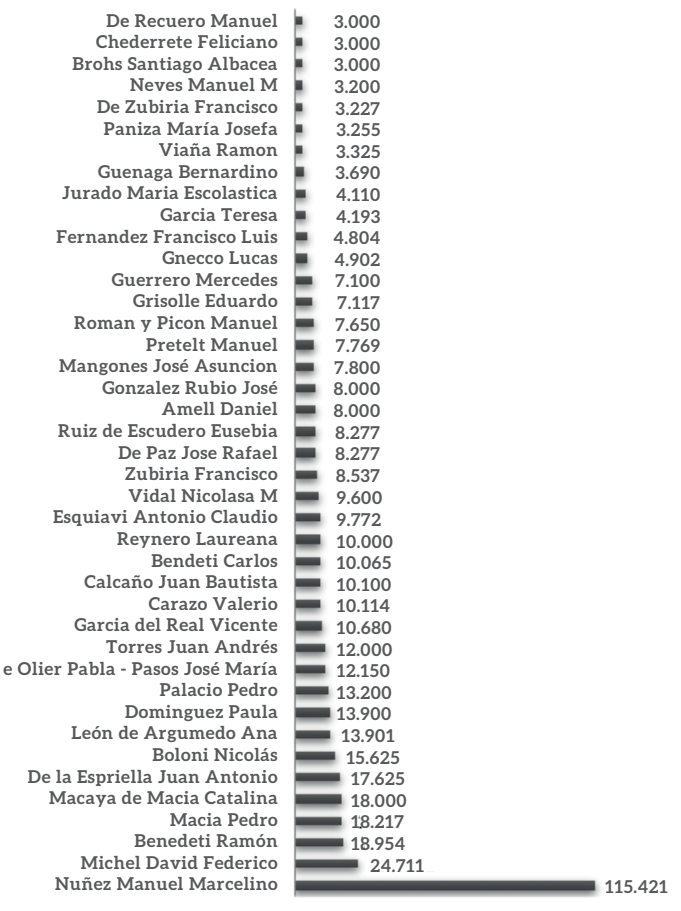

Fuente: Elaboración Propia. AHC, Protocolos Notariales, Notaría Primera, 1830-1851

22. AHC, Protocolos Notariales, Notaría Primera, 1830-1851. 
Como Bonoli, otros comerciantes estaban en una situación similar. Vale la pena destacar que algunas de las mujeres que participaban en la compraventa de esclavos lo hicieron en la de casas, por ejemplo, Ana León de Argumedo, la máxima vendedora y compradora de esclavos en los años de estudio, si bien no aparece entre las primeras treinta compradoras de casas, logró un monto en ventas de 13.901 pesos, mientras que María Josefa Paniza aparece comprando por valor de 7.117 pesos y vendiendo por 3.255 pesos; Rafaela Polanco compra por 11.609 pesos y su esposo Manuel Román y Picón vende por 7.650 pesos. Entre tanto, Senén Benedetti, quien está vinculado al comercio de exportación y también participa en la compraventa de esclavos, vendió casas por un monto de 10.065 pesos, y Francisco De Zubiría, comerciante reconocido, vendió por un valor de 11.714 pesos ${ }^{23}$.

Entre los años analizados se remataron 23 casas de diferentes condiciones, en especial de piedra, madera y teja y de planta baja por un monto de 32.159 pesos. Entre los compradores se destacan José Pablo Rodríguez De La Torre, quien invierte un capital de 6.000 pesos; Pedro Marcelino Sierra, de 4.000 pesos; Juan de Francisco Martín, de 3.501 pesos; José Hernández, de 4.300 pesos y Ramón Benedetti, de 800 pesos, entre otros.

No cabe duda de que la compraventa de casas tuvo un papel clave en los flujos económicos que se dieron durante los años de crisis y en el proceso de consolidación de algunos comerciantes en la ciudad que, sin ninguna liquidez, con estas transacciones lograron insertarse en las actividades comerciales de la ciudad y, en algunos casos, en el comercio internacional ${ }^{24}$.

\section{LAS COMPRAVENTAS Y EL COMERCIO INTERNACIONAL EN CARTAGENA}

Un análisis general sobre las tendencias de la compraventa en los años de estudio revela conclusiones interesantes. La primera es que el monto total de las transacciones en estas dos actividades (compraventa casas y esclavos) ascendió a 1.077.534 pesos, lo que en 21 años, caracterizados por la crisis, se convierte en una cifra importante. En este valor la compraventa de casas participó con el $80 \%$, equivalente a un capital de 893.608 pesos ${ }^{25}$, mientras que la compraventa de esclavos participó con el $20 \%$, representado en un capital de 183.926 pesos.

La segunda conclusión interesante es que estas transacciones se disparan en cantidad y valor en los años posteriores a eventos particulares, como contiendas civiles y proliferaciones epidémicas. En efecto, después del sitio de Cartagena, en 1831, los conflictos diplomáticos de 1833 y 1834 con Francia, el ataque de viruela en 1839-1840, la guerra de los supremos que se desarrolla entre 1840-1842 y, al parecer, la epidemia del cólera morbo, en 1849, se experimenta un aumento significativo de las transacciones comerciales de compraventa. Ver la siguiente gráfica:

\footnotetext{
23. AHC, Protocolos Notariales, Notaría Primera, 1830-1851.

24. Para un análisis de la economía monetaria y el rol del río Magdalena ver Vidal y Castillo (2016). Enlazando la nación. Del río Magdalena al Gran Caribe, 1840-1890. En Román Raúl, Economía del caribe colombiano y construcción de nación 1770-1930. Bogotá: Universidad Nacional de Colombia.

25. Este valor es inferior al real y no incluye, como se mencionó, 52 compraventas que no lo tenían en los registros notariales. En calculo promedio ascienden a un valor de 83.275 pesos. Tampoco incluye los remates de casas, que llega a un monto de 32.159 pesos, que suman en total aproximado de 115.434 pesos.
} 
Gráfica 9. Tendencia en las transacciones de compraventas de esclavizados y casas

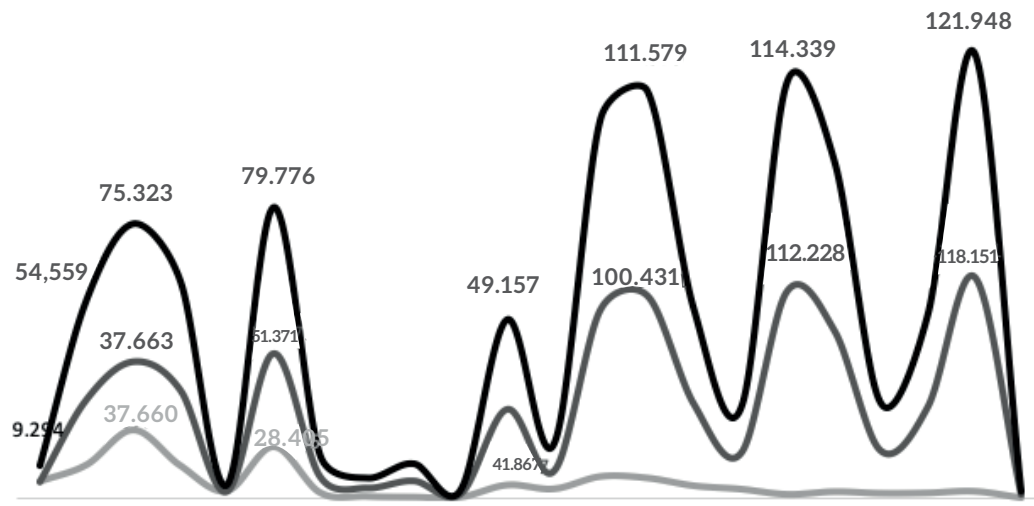

Año 18301831832183318341835183618371838183918401841184218431844184518461847184818491850

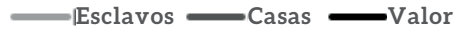

Fuente: Elaboración Propia. AHC, Protocolos Notariales, Notaría Primera, 1830-1851

Sin duda, estas coyunturas particulares de orden público y de crisis en la salud pública dinamizaron las prácticas especulativas en la ciudad, que están en relación directa con las transacciones de casas y esclavizados. En este aumento repentino de las transacciones económicas las compraventas de casas tienen el $80 \%$ de la participación, porque, como se puede observar en la gráfica, la compraventa de esclavizados es más sostenida en los primeros cinco años de la década del treinta y luego disminuye hasta la época de la Guerra de los Supremos ${ }^{26}$.

\section{Gráfica 10. Tendencia de las exportaciones, importaciones exportación de frutos y} compraventas de esclavizados y casas, 1830-1851

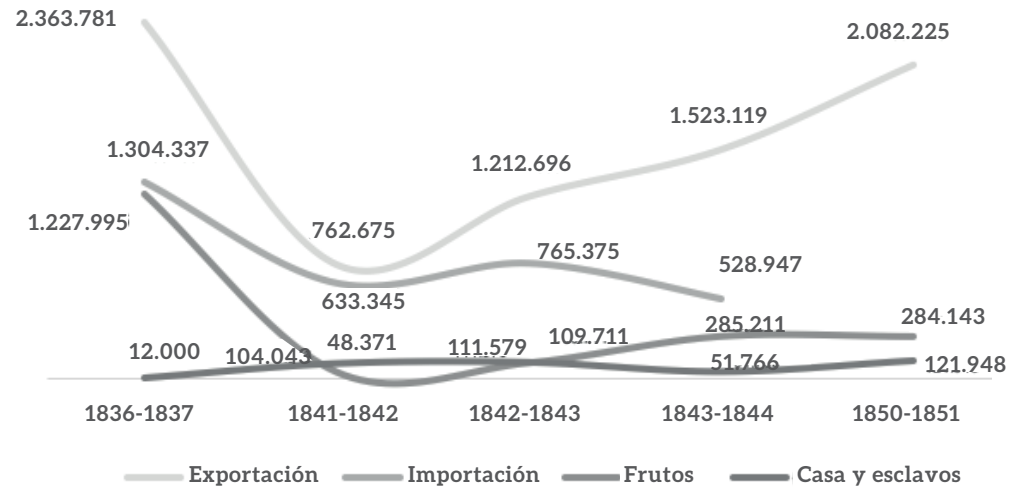

Fuente: Elaboración Propia. AHC, Protocolos Notariales, Notaría Primera, 1830-1851.

26. Un análisis de la compraventa de la propiedad raíz en santa Marta puede analizarse en: Elías (2010). El puerto de Santa Marta: determinantes del crecimiento y desarrollo de una ciudad caribeña 1810-1860. En: Elías Jorge y Vidal Antonino (eds), Ciudades portuarias en la Gran Cuenca del Caribe, Barranquilla: Universidad del Norte, Universidad del Magdalena. 
Otro aspecto importante es la participación de estas compraventas en el comercio de las exportaciones e importaciones, donde, por su puesto, no participan con porcentajes amplios en términos generales, pero tienen gran importancia si se observan las transacciones mercantiles a menor escala, ya que los comerciantes, en la mayoría de los casos que se han visto afectados por las consecuencias de la larga guerra de independencia y los conflictos bélicos, no realizan grandes inversiones ni asumen riesgos que comprometan sus capitales. Por lo regular, estos comerciantes hacían operaciones muy seguras a pequeña escala con inversiones mínimas. Muchos lograron, de manera individual o como agentes de casas comerciales, que les consignaran las mercancías y posteriormente realizaban los pagos ${ }^{27}$.

Como se puede apreciar, las tendencias de los diferentes comercios en los años en que se cuenta con datos para realizar la comparación tienen diferencias: primero el comercio de exportación presentó una caída durante la Guerra de los Supremos para, posteriormente, iniciar un proceso sostenido de ascenso; segundo, las importaciones en general presentan una tendencia hacia la baja; tercero, las exportaciones de frutos del año económico 18361837 a 1841-1842 presentan una baja y a partir de allí inician un aumento lento y estable. A mediados de la década del cuarenta presentan una disminución y aumentan a inicios de los años cincuenta, como se puede apreciar en la siguiente tabla.

Tabla 4.

Posible participación de la compraventa de casas y esclavizados en el comercio de importación y exportación, 1836 -1851

\begin{tabular}{c|c|c|c}
\hline Año & $\begin{array}{c}\text { Total de importaciones } \\
\text { y exportaciones }\end{array}$ & $\begin{array}{c}\text { Total de compraventa } \\
\text { de casas y esclavizados }\end{array}$ & $\begin{array}{c}\text { Participación porcentual } \\
\text { de estas compraventas }\end{array}$ \\
\hline $1836-1837$ & 3.668 .118 & 1.2000 & 0,33 \\
$1841-1842$ & 1.396 .020 & 10.4043 & 7,45 \\
$1842-1843$ & 1.978 .071 & 11.1579 & 5,64 \\
$1843-1844$ & 2.052 .067 & 5.1786 & 5,56
\end{tabular}

Fuente: Elaboración Propia con base en AHC, Protocolos Notariales, Notaría Primera, 1830-1851.

Aunque esta tendencia no parece decir mucho aisladamente, lo cierto es que el comercio de casas y esclavos tuvo un papel clave en la economía de la ciudad y pudo representar una participación en el comercio internacional de pequeña consideración, especialmente en los años económicos 1841 a 1843, cuando alcanza un 14\%. Lamentablemente no 
disponemos de más datos que permitan establecer una serie completa del comercio internacional para compararlo año por año y determinar la incidencia que pudo tener en el capital derivado de las compraventas. Lo que sí podemos hacer es relacionar estas compraventas con cada uno de los comercios que se hicieron por el puerto para comprender de mejor manera cómo estas compraventas se articulaban a la economía de una ciudad en crisis.

En la siguiente tabla podemos observar la posible participación en términos porcentuales de las compraventas, primero en las exportaciones, segundo en las importaciones y tercero en las exportaciones de frutos, donde participaba un número importante de comerciantes con pequeñas inversiones y sin ningún tipo de riesgos.

Tabla 5.

Posible participación de la compraventa de casa y esclavizados en el comercio de exportación, importación y exportación de frutos

\begin{tabular}{|c|c|c|c|c|c|c|c|}
\hline \multirow{2}{*}{ Año } & \multirow{2}{*}{ Exportación } & \multirow{2}{*}{ Importación } & \multirow{2}{*}{ Frutos } & \multirow{2}{*}{$\begin{array}{c}\text { Casa y } \\
\text { esclavizados }\end{array}$} & \multicolumn{3}{|c|}{$\begin{array}{l}\text { Posible participación porcentual de la } \\
\text { compraventa de esclavos y casas }\end{array}$} \\
\hline & & & & & $\begin{array}{c}\% \\
\text { Exportaciones }\end{array}$ & $\begin{array}{c}\% \\
\text { Importaciones }\end{array}$ & 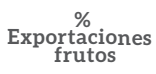 \\
\hline $1836-1837$ & 2.363 .781 & 1.304 .337 & 1.227 .995 & 12.000 & 0,5 & 0,9 & 1 \\
\hline $1841-1842$ & 762.675 & 633.345 & 48.371 & 10.4043 & 13,6 & 16,4 & 215 \\
\hline $1842-1843$ & 1.212 .696 & 765.375 & 1.097 .107 & 111.579 & 9,2 & 14,6 & 102 \\
\hline $1843-1844$ & 1.523 .119 & 528.947 & 285.211 & 51.786 & 3,4 & 9,8 & 18 \\
\hline $1850-1851$ & 2.082 .225 & & 284.143 & 121.948 & 5,9 & & 43 \\
\hline
\end{tabular}

Fuente: Elaboración Propia con base en AHC, Protocolos Notariales, Notaría Primera, 1830-1851

A menor escala se observa la importancia que, de seguro, tuvieron estas transacciones comerciales de compraventa en el comercio internacional en el caso de las exportaciones. Los años económicos donde hubo mayor incidencia de las mismas fueron de 1841 a 1843 , un bienio que alcanzó una participación de más del 22\%. En el caso de las importaciones, estos mismos dos años pudieron participar con el 31\%, lo cual es significativo. Entre tanto, respecto a la exportación de frutos, donde las compraventas de estos mismos dos años superan el valor de los frutos exportados, se tendría una participación importante ${ }^{29}$.

Estas escalas comparativas dan algunas certezas sobre la importancia que tuvieron estas transacciones de compraventa en la economía de la ciudad. Las compraventas en general funcionaron para muchos comerciantes como un elemento de financiación de negocios, sobre todo si se aprecian en un contexto en el que la ciudad está en un declive económico y la mayoría de los comerciantes en quiebra y escasamente realizan tímidas inversiones.

29. Un análisis sobre el funcionamiento de los créditos y los réditos en la economía cartagenera de finales del siglo XVIII y principios del siglo XX puede verse en Marchena (2000). Capital, créditos e intereses comerciales a fines del periodo colonial: los costos del sistema defensivo americano. Cartagena de Indias y el sur del Caribe", en: Estudios n9, Barcelona: Universitat Jaume I Castellon. 
Muchos comerciantes tienen una práctica casi que para la subsistencia y son muy pocos los excedentes que logran para invertir a gran escala, como sucede en otros contextos, quizá por esa razón, la capitalización de muchos de estos, pese a la especulación reinante, fue difícil, más aún la inversión en proyectos económicos rentables (Román, 2010).

\section{CONCLUSIONES}

El declive económico que experimentó Cartagena de manera vertiginosa después de la Independencia prolongó la comercialización y la especulación con los esclavizados y los bienes raíces, de esta manera las compraventas se convirtieron en un elemento de financiación de actividades comerciales para un grupo de individuos, tanto hombres como mujeres, que participaron activamente de los negocios que se daban en el puerto.

La incapacidad económica de estos comerciantes y sus limitaciones financieras impidieron que se superara la crisis, pues no arriesgaron capitales ni invirtieron en proyectos empresariales o productivos, hecho que no sólo impidió que las condiciones materiales y la capacidad que tenía la ciudad y la provincia de Cartagena se desarrollaran, sino también los obligó a demandar por parte del Gobierno una política económica favorable para sus actividades económicas. Un reducido grupo de comerciantes cartageneros promovió diversos proyectos para sacar el puerto y la provincia del estado de penuria en que se encontraban, sin embargo, estos proyectos generaron confrontaciones con el Gobierno central, con los comerciantes de Bogotá y los de otros puertos de la región Caribe, en un momento en el que se disputaban los espacios económicos del naciente Estado neogranadino.

\section{REFERENCIAS BIBLIOGRAFICAS}

Archivo Histórico de Cartagena (AHC), Protocolos Notariales, Notaría Primera. 1830-1851.

Archivo General de la Nación (AGN) Fondo Enrique Ortega Ricaurte, caja 102, Carpeta 373, f, 887

Bell Lemus, G. (1990). Cartagena de Indias de la colonia a la República. Bogotá: Fundación Guberek.

Belmonte, J. L. (2011). Ser esclavo en Santiago de Cuba. Espacios de poder y negociación en un contexto de expansión y crisis 1780-1803. Madrid: Editorial Doce Calles.

Calvo Stevenson, H. (2002). A la sombra de la Popa: El declive de Cartagena en el siglo XIX. En Calvo H., y Meisel, A. (eds) Cartagena de Indias en el Siglo XIX. Bogotá: Universidad Jorge Tadeo Lozano-Banco de la República.

Corrales, M. E. (1888). Anales del Estado soberano de Bolívar, Tomo IV. Cartagena.

Corrales, M. E. (1999). Efemérides y anales del Estado Soberano de Bolívar. Bogotá: Gobernación de Bolívar, Instituto Internacional de Estudios del Caribe. 
Elías Caro, J. (2010). El puerto de Santa Marta: determinantes del crecimiento y desarrollo de una ciudad caribeña 1810-1860. En Elías J. y Vidal A. (eds), Ciudades portuarias en la Gran Cuenca del Caribe. Barranquilla: Universidad del Norte, Universidad del Magdalena.

Gosselman, C. A. (1981). Viaje por Colombia, 1825-1826. Bogotá: Archivo de la Economía Nacional, Banco de la República.

Hevia, O. (2017). Mujeres negras y mulatas en la economía de servicios en La Habana colonial siglos XVI y XVII. En Piqueras, J.A. (ed), Plantación espacios agrarios y esclavitud en la cuba colonial. Habana: Casa de Las Américas- Universidad Jaume I

Klein, H. (2002). El Comercio atlántico de esclavos en el siglo XIX y el suministro de mano de obra en Cuba y Brasil. En: Piqueras José Antonio (ed.) Azúcar y esclavitud al final del trabajo forzado. Madrid: Fondo de Cultura Económica

Marchena Fernández J. (2000). Capital, créditos e intereses comerciales a fines del periodo colonial: los costos del sistema defensivo americano. Cartagena de Indias y el sur del Caribe, en: Estudios $n^{\circ} 9$. Barcelona: Universitat Jaume I.

Meisel, A. (1989). Esclavitud, mestizaje y Haciendas en la provincia de Cartagena, 1533-1551. En Bell Lemus Gustavo (ed), El Caribe Colombiano, Barranquilla: Universidad del Norte.

Meisel A. (2016). La estructura económica de San Andres y Providencia en 1846. En Román Raúl, (ed) Economía del caribe colombiano y Construcción de nación 1770-1930. Bogotá: Universidad Nacional de Colombia.

Moreno Fraginal, M. (1978). El ingenio complejo económico social cubano del azúcar. La Habana: Ciencias Sociales.

Múnera A. (2008). El fracaso de la nación, región, raza y clase en el Caribe. Bogotá: Norma.

La Democracia, Cartagena, febrero 7 de 1853

Posada Carbó, E. (1994). Progreso y estancamiento, en: Meisel Adolfo (ed) Historia económica y social del Caribe colombiano. Barranquilla: Editorial Uninorte.

Piqueras, J. A. (2017). Plantación espacios agrarios y esclavitud en la cuba colonial. Habana: Casa de Las Américas-Universidad Jaume I.

Restrepo, J.,y Rodríguez, M. (1986). La actividad comercial y el grupo de comerciantes de Cartagena finales del siglo XIX. En Estudios Sociales $\mathrm{N}^{\circ}$ 1, Medellín. 
Ripoll, M. T. (1994). La elite en Cartagena y su tránsito a la república. Revolución política sin revolución social. Bogotá: Universidad de los Andes.

Ripoll, M. T. (2000). Tradición mercantil en Cartagena en Cartagena en el siglo XIX, en, Calvo S., Haroldo- Meisel, Adolfo (eds), Cartagena de Indias en el Siglo XIX. Cartagena: Banco de la República.

Román, R. (2010). La crisis del puerto de Cartagena de Indias: conflictos y fracasos en sus proyectos de desarrollo 1830-1848 en: Elías Caro Jorge y Vidal Ortega Antonino (eds), Ciudades portuarias en la Gran Cuenca del Caribe. Barranquilla: Universidad del Norte, Universidad del Magdalena

Román, R. y Vidal, A. (2011). El Caribe Colombiano versus centro del país: rivalidades economías en la construcción de una economía nacional. Investigación y Desarrollo, Vol. 19, 1, 140-165.

Román R. (2016). Productividad y condiciones económicas de la provincia de Cartagena en la primera mitad del siglo XIX, en. Economía del caribe colombiano y Construcción de nación 1770-1930. Bogotá: Universidad Nacional de Colombia.

Romero D. (1997). Esclavitud en la provincia de Santa Marta 1791-1851, Santa Marta: Fondo de autores magdalenenses, Instituto de Cultura y Turismo del Magdalena.

Semanario de la Provincia de Cartajena, Cartagena, julio 22 de 1849

Segovia Salas R. (1967). Teoría de Cartagena porque se pierde un siglo, en: Bossa Herazo, Donaldo, Cartagena independiente. Tradición y desarrollo. Bogotá: Tercer Mundo.

Solano, S. (1994). Empresarios, proyectos de modernización e imaginarios sociales en la provincia de Cartagena durante la primera mitad del S XIX, en, Historia y cultura, $\mathrm{N}^{\circ} 3$, Universidad de Cartagena.

Tomich D. (1998). The second slavery: Bonded labor and the transformation of the Nineteenth Century world economy, en: Ramirez Francisco, (ed.) Rethinking the nineteenth century: movements and contradictions. Westport: Greenwood press.

Vidal, A. y Castillo, G. (2016). Enlazando la nación del rio Magdalena al Gran Caribe, 1840-1890, en Román Romero Raul, Economía del caribe colombiano y Construcción de nación 1770-1930, Bogotá: Universidad Nacional de Colombia.

Vidal, A. y Ramos, J. (2019). Labradores y esclavizados de la isla de San Andrés en el comercio del Caribe occidental y América Central a finales del siglo XVIII, en Román Romero Raúl y Vidal Ortega Antonino (Eds) Memorias, historias y olvidos Colonialismo, sociedad y política en San Andrés y Providencia. Bogotá: Universidad Nacional de Colombia. 